\title{
Antecedents and consequences of compulsive buying behaviour: the moderating effect of financial management
}

\author{
Godfred Matthew Yaw Owusu, Rita Amoah Bekoe, Miriam Arthur and \\ Theodora Aba Abekah Koomson \\ Department of Accounting, University of Ghana Business School, Accra, Ghana
}

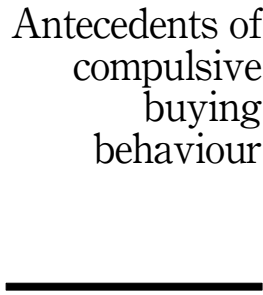

Received 24 April 2021 Revised 5 June 2021 Accepted 3 September 2021

\begin{abstract}
Purpose-This paper investigates the determinants of compulsive buying behaviour (CBB) and ascertains the effect of $\mathrm{CBB}$ on the propensity of an individual to be dependent on loans and fall into financial trouble. The study additionally examines the moderating effect of financial management on the hypothesized relationships. Design/methodology/approach - The survey method of research was adopted using questionnaires as the principal means of data collection. The predicted relationships of the study were tested using the partial least square structural equation modelling technique.

Findings - The authors' results suggest materialism, socioeconomic status and financial management skills of an individual are significant predictors of CBB. The authors also find CBB to be positively associated with loan dependence and the authors' analysis suggests financial management skills moderate the hypothesized relationships. Social implications - Findings of this study suggest buying compulsively increases the risks of overdependence on loans and can be indirectly associated with the risk of individuals falling into financial trouble. Originality/value - The findings highlight the adverse effects of CBB on loan dependence and financial trouble and the moderating effect of financial management on the dominant factors that influence CBB.
\end{abstract}

Keywords Financial management, Compulsive buying behaviour, Financial trouble, Loan dependence, Materialistic value

Paper type Research paper

\section{Introduction}

Studies into shopping and buying behaviour of people argue that although the essence of shopping traditionally is to satisfy utilitarian needs of individuals, the objective of shopping in contemporary times for some individuals goes beyond the satisfaction of utilitarian needs. While shopping is considered by some as a leisure activity and a form of entertainment, others use shopping to manage their emotions and express self-identity (Black, 2007; Dittmar, 2005; Hudson et al., 2017). However, a major challenge often associated with shopping meant to serve other purposes other than utilitarian is that it can sometimes lead to uncontrolled buying behaviour especially for people plagued with self-control issues. Commonly described as compulsive buying behaviour (CBB), the concept has been conceptualized as a chronic tendency to spend beyond one's needs and means occasioned by the gratification of the inner urge to make repeated purchases in order to provide relief from mental disquiet (Mittal et al., 2008).

(C) Godfred Matthew Yaw Owusu, Rita Amoah Bekoe, Miriam Arthur and Theodora Aba Abekah Koomson. Published in Journal of Business and Socio-economic Development. Published by Emerald Publishing Limited. This article is published under the Creative Commons Attribution (CC BY 4.0) licence. Anyone may reproduce, distribute, translate and create derivative works of this article (for both commercial and non-commercial purposes), subject to full attribution to the original publication and authors. The full terms of this licence may be seen at http://creativecommons.org/licences/by/4.0/ legalcode

This study was funded by the University of Ghana Business School Faculty Research Grant.

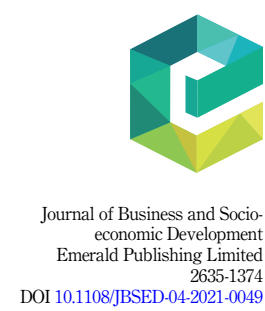


According to Aw et al. (2018) buying becomes compulsive when accompanied by a seemingly beneficial component often used as a means of coping with disappointment, frustration or even a distortion of autonomy. Buyers in this category in effect have the urge and intense desire to obtain possessions regardless of the harmful psychological and financial consequences (Iqbal and Aslam, 2016). Closely related to this abnormal shopping behaviour and sometimes mistakenly used interchangeably is the concept of impulsive buying. Yingjiao (2008), however, points out that while compulsivity deals with being plunged into venturing to blunt negative events and feelings, individuals who are impulsive buyers tend to employ buying as a strategy to seek pleasure, arousal and self-gratification. When buying impulsively becomes entrenched (a frequent strategy for an individual's mood repair), it gives rise to compulsive buying (Silvera et al., 2008). Notwithstanding the conceptual differences, it has been acknowledged that compulsivity and impulsivity tendencies can exist simultaneously in the same individual, even though the emotional triggers associated with each may be different (Flight et al., 2012).

Classified as the worse form of buying behaviour, CBB has been recognized as a growing global problem among consumers particularly students having been associated with a number of undesirable outcomes (Mestre-Bach et al. 2017; Palan et al., 2011). Black (2007), for instance, concludes that $85 \%$ of individuals who are compulsive buyers tend to have debt related problems with $74 \%$ of them usually with debt levels out of control. In part, the surge in this unusual behaviour has been attributed to the incessant desire of individuals to consume, the appetite for material things and the culture of using material possessions as a symbol of status and show of power in society (Chaplin and John, 2007; Palan et al., 2011). Indeed, Islam et al. (2018) posit that material possession is seen by compulsive buyers in particular as a way to happiness, success and self-identity.

The relationship between materialism and $\mathrm{CBB}$ has therefore, been a subject of interest to many academic researchers. While some existing studies have shown that materialism correlates positively with CBB (Islam et al., 2018), the current study provides some new perspective on the materialism and $\mathrm{CBB}$ nexus from an African context. Notwithstanding the fact that the evidence from this context is relevant given the scarcity of research on this subject from the African context, our study contributes theoretically to the literature in three important ways.

First, in addition to materialism, we examine other predictors of $\mathrm{CBB}$ by highlighting the role of time affluence and socio-economic status of an individual on the tendency to buy compulsively. We argue that individuals with a lot of time at their disposal are more likely to buy compulsively given that such individuals tend to experience negative emotional states like anxiety, insecurity, guilt and often cope poorly with boredom (Giluk and Postlethwaite, 2015). Heightened levels of stress may induce compulsive buying in time affluent individuals. Also, this study argues that individuals who perceive high social status as desirable are more prone to buy compulsively. The quest for recognition of status may be associated with CBB because of the believe that the frequency of buying status products or owning a number of possessions matters for an individual's status (Wang and Tsai, 2017).

Second, we examine some outcomes of $\mathrm{CBB}$ by highlighting its impact on loan dependence and financial trouble. This study argues that $\mathrm{CBB}$ could lead to dependence on loans and advances by individuals as the cycle of purchases continue and the individual is unable to fund future purchases from personal resources. The increasing reliance on loans to finance such a behaviour exposes such individuals to the risk of falling into financial trouble.

Third, this study uniquely examines whether financial management skills can moderate favourably the perceived impact of materialism, time affluence and socio-economic status on $\mathrm{CBB}$. Empirical studies on financial management have shown that the frequency with which individuals with strong financial management background buy compulsively is by far less compared to individuals who have not mustered this skill (Wang and Tsai, 2017). On the basis 
of this, we argue that the effect of materialism, time affluence and socio-economic status on $\mathrm{CBB}$ could change in the presence of strong financial management skills.

The rest of the article is organized as follows: the next section reviews literature on compulsive buying behaviour and the key constructs of the study followed by the hypotheses of the study. The subsequent section discusses the research methodology. Discussion of the study results follows and the paper ends with concluding remarks.

\section{Literature review and hypotheses development}

Buying behaviours and the concept of compulsive buying behaviour (CBB)

$\mathrm{CBB}$ refers to the incessant and buying without respite to make up for a void created in life as a result of negative feelings or emotions (Johnson and Attmann, 2009). CBB falls under the three specific behaviours under the consumer buying process: rational, impulsive and compulsive buying (Sulehri and Ahmed, 2017). In terms of order, the buying process usually begins with the rational buying which basically entails the execution of planned purchases and sticking to budget control. A "rational buyer" therefore plans and carefully allocate resources before the actual acquisition is made. A shift from this rational process by an individual leads to the impulsive state of buying. According to Risqiani (2015) impulsive state of buying involves the prompt decision of making unplanned purchases subconsciously. Closely related to impulsive buying is the concept of compulsive buying which has been described as an impulsive disorder (Asad Shahjehan, 2012). Kellett and Bolton (2009) intimate that compulsivity sets in at the stage where there is a failure of impulse control backed by the need to repair the mood of the individual. As Moon et al. (2015) point out individuals are able to lighten their mood by gaining control over their boredom, stress, and anxiety through the act of buying compulsively.

A distinguishing factor between $\mathrm{CBB}$ and the other buying behaviours is the strong and irresistible urge to buy that accompanies it (Donnelly et al., 2016). Compulsive buyers almost always possess persistent obsessions, anxiety reactions, higher levels of depression, lower self-esteem, weaker impulsive control, stronger desire for superior achievement and the greater tendency for approval (Iqbal and Aslam, 2016; Johnson and Attmann, 2009).

\section{Hypotheses development}

The tendency to buy compulsively is influenced by a multiplicity of factors. Following prior literature however (Ahmed, 2018; Islam et al., 2018; Khandelwal et al., 2021; Manolis and Roberts, 2012), three factors - materialism, socio-economic status, time affluence - which have been found on a consistent basis to be good predictors of $\mathrm{CBB}$ are examined in this study. Also, we investigate the role of financial management on $\mathrm{CBB}$ and further predict that the effect of materialism, socio-economic status, time affluence on $\mathrm{CBB}$ could be moderated by financial management skills of an individual. Lastly, the framework also suggests CBB may be associated with loan dependence and financial trouble.

\section{Materialism and $C B B$}

Considered to be an intense desire to give relevance to material possessions, the concept of materialism has been a key focus for studies into psychological aspect of consumer behaviour (Dittmar, 2005; Dittmar et al., 2014; Iqbal and Aslam, 2016). Materialism has been conceptualized to mean that material possessions constitute an important part of an individual's happiness in life (Richins and Dawson, 1992). According to Richins (2004), a highly materialistic person believes in the acquisition of material goods as a key indicator of success, a measure of self-identity, and central to life goal. Such individuals are attention seeking, love to impress others and value highly the acquisition of objects (Iqbal and Aslam,
Antecedents of compulsive buying behaviour 
2016; Martinez-Novoa and Hodges, 2016a; Pham et al., 2012). Because of their materialistic pursuit, such individuals have pro-spending attitudes usually aimed at owning material possessions. According to Pham et al. (2012), compulsive buyers do not only have strong emotional attachment to material possessions but also derive some form of relief from negative emotions through the acquisition of material things. Buying compulsively is also a means by which some individuals repair their negative emotions (Ching and $\mathrm{Wu}, 2018$ ), rebuild their self-esteem (Martinez-Novoa and Hodges, 2016b), obtain pleasure, arousal and gratification from material goods (Hollander and Rosen, 1998). The expression of materialistic pursuit implies that materialistic individuals would do whatever it takes to be recognized as wealthy, hence would be engaged in constant purchases of material goods.

Empirically, findings by many extant studies (Donnelly et al., 2016; Pham et al., 2012; Yingjiao, 2008) support the assertion that individuals with high materialistic values are more prone to buy compulsively. On the basis of this, this study hypothesized that:

H1. A positive relationship exists between materialistic values and CBB.

\section{Socio-economic status and $C B B$}

Socioeconomic status (SES) plays a crucial role in the wellbeing of people, their education, their psychological, physical and mental health. The term SES refers to the level of comfort in the lives of people as well as the sort of opportunities and privileges accorded them in society. Oakes (2012) argues that individuals with high socio-economic status are generally wealthy as such have a high frequency of buying luxury products which reaffirms their identity and high standing in society. Individuals with high SES have an orientation to promptly satisfy their gratifications and love to be noticed by all (Adler and Ostrove, 1999; Gaur, 2013; Huang and Hsieh, 2011; Oakes, 2012). Because of their recognition seeking nature, such individuals get upset when they feel less valuable or important. Owing to this, they are intrinsically motivated to buy compulsively in hope of getting the attention they require.

Empirically, SES has been associated with the inclination to buy compulsively CBB (Cirino et al., 2002; Mestre-Bach et al., 2017). Thus, we hypothesize that:

\section{H2. A positive relationship exists between SES and CBB.}

\section{Financial management and compulsive buying}

Financial management generally refers to being in the position of exerting self-mastery over mundane finances and recognizing traces of financial shocks to be tackled. A key to financial management are the ability to fulfil financial goals and being able to find life appealing as a result of being unburdened financially (Maraz et al., 2015). Financial management skills are essential in promoting responsible financial behaviour. As a concept, individuals with proper financial management skills usually have lower compulsive buying tendencies. Lim et al. (2017) argue that such individuals are discipline and cope better with uncertainties. Several studies (Lim et al., 2017; Ramalho and Forte, 2019) have provided results consistent with the fact that financial management is negatively associated with compulsive buying behaviour.

This study therefore hypothesizes that:

H3. A negative relationship exists between financial management skills and CBB.

\section{Time affluence and $C B B$}

Time has been accorded much prominence in recent times. As a concept, Time Affluence describes the sense of having enough time to explore one's own interests and thoughts. Individuals who rank high on the time affluence scale are deemed time affluent while 
individuals who feel their lives are rushed or busy rank low on the time affluence scale (Manolis and Roberts, 2012). As Manolis and Roberts (2012) opine, individuals with high levels of engagement in activities (low time affluence) may resort to acts of buying as an avenue of handling and alleviating stress associated with hectic schedules. Such individuals according Lajeunesse and Rodríguez (2012) may buy compulsively with the intention of coping with stress and other negative emotions that come with their tight schedules. Thus, engaging in compulsive buying is a means by which some individuals who rank low on time affluence deal with their negative emotions. Generally, the argument that low time affluence influences individuals to buy compulsively is supported by many empirical studies (Gärling et al., 2014; Kasser and Sheldon, 2009; Lajeunesse and Rodríguez, 2012; Nilsson et al., 2017). Based on this, this study hypothesized that:

H4. A positive relationship exists between low time affluence and CBB.

\section{$C B B$ and loan dependence}

Buying compulsively could have dire financial consequences for an individual. A common practice by compulsive buyers is the dependence on loans to finance their purchases. The argument is that such individuals consider buying of things as a means of alleviating unpleasant emotions and hence, may resort to borrowing when personal resources are not enough to finance the desire to purchase things (Black, 2007). Credit card debt, personal loans and advances are amongst the many forms loan dependence takes (Duh and Thorsten, 2019; Maraz et al., 2015; Mccarthy, 2011; Prawitz et al., 2006). Individuals who engage in compulsive buying struggle to control spending and may end up in high debt (Achtziger et al., 2015). In line with the proposition by Aw et al. (2018), this study posits that individuals with high compulsive buying tendencies are more likely to rely on other external parties or sources such as buying on credit and advances from financial institutions. Therefore, this study hypothesizes that:

H5. A positive relationship exists between $\mathrm{CBB}$ and loan dependence.

\section{Loan dependence and financial trouble}

Compulsive buyers who have access to credit facilities usually have an erroneous mental representation of being in control of their purchases (Aw et al., 2018). This illusion drives such individuals to unconsciously keep buying incurring excessive debts in the process. Such individuals therefore risk falling into financial trouble defined as the inability to make basic payments or promptly fulfil loan instalments (Black, 2007). Existing studies (Achtziger et al., 2015; Brougham et al., 2011; Roberts and Jones, 2001) generally conclude that compulsive buyers who are loan dependent tend to have difficulty in fulfilling their debt obligations and risk running into financial problems such as insolvency.

Accordingly, this study hypothesizes that:

H6. A positive relationship exists between loan dependence and financial trouble.

\section{The moderating role of financial management}

Financial management skills have implications on the savings and spending behaviour of individuals. Individuals with proper financial management skills do not spend or use money indiscriminately and tend to have some level of control over spending, especially, the unplanned ones. However, when financial management skills are weak, the tendency for an individual to spend and buy compulsively will be high (Duh and Thorsten, 2019). Accordingly, this study examines the effect of individuals' financial management skills on the predictors of CBB. Specifically, we argue that the effect of materialism, SES and time 
affluence on $\mathrm{CBB}$ will vary in the presence of strong financial management skills. Again, it is predicted that the urge to depend on loans for a compulsive buyer is likely to change when financial management background of the individual is strong. Accordingly, the following hypotheses are proposed:

H7. Financial management moderates the relationship between materialism and CBB.

H8. Financial management moderates the relationship between SES and CBB.

H9. Financial management moderates the relationship between time affluence and CBB.

H1O. Financial management moderates the relationship between $\mathrm{CBB}$ and loan dependence.

\section{Methodology}

Population, sampling technique and sample size

All business students in the University of Ghana Business school constituted the population of this study. Data was collected using multi-stage sampling technique by first classifying the population into the different department in the business school. Each department was further classified into four groups based on the different academic levels. This approach was adopted to improve the representativeness of the sample and to account for the differences in some key demographic characteristics of the respondents in our analysis. A total of 500 questionnaires were administered to different groups during class sessions in the first semester of 2019/2020 academic year. To ensure voluntary participation, encourage honest responses and minimize socially desirable responses from respondents, the purpose of the survey was explained to them, and respondents were assured of confidentiality of their responses. A total of 477 valid responses were used for the analysis out of the 500 questionnaires that were administered.

\section{Descriptive characteristics of respondent}

The questionnaire contained information on the demographic characteristics of respondents including the gender, age, year of study, course majors and socio-economic status (SES). Following prior studies (Abraham, 2016; Gaur, 2013; Huang and Hsieh, 2011) we measured the SES of our respondents who belonged to the youthful age group by reference to the educational level, occupation and housing status of their parents details of which are presented in Table 1. From the descriptive statistics shown in Table 1, there was almost an equal distribution of males and females with the females outnumbering the males by 48 . Majority of the respondents were between the ages of 18-22 (83\%) an indication the sample respondents belong to a very youthful population. Students in their final year constituted almost half of the respondents $(43.2 \%)$ distantly followed by the second-year students. The socioeconomic information shows majority of the students are in the upper class (43\%), with $33.3 \%$ of the respondents in the middle-class status. Details of the characteristics of the respondents are shown in Table 1.

\section{Measurement of study construct}

The dependent variable of the study, CBB, was measured by adopting the Faber and Christenson (1996) scale which assesses thoughts, effects and behaviour (before, during and after the purchase) and has been employed in many empirical studies (Iqbal and Aslam, 2016; Martinez-Novoa and Hodges, 2016a). Materialistic value was measured using the materialism scale (Rindfleisch et al., 1997) while the indicators of personal financial management behaviour were adopted from Parrotta and Johnson (1998). Time affluence was measured 


\begin{tabular}{|c|c|c|c|c|}
\hline Demographic variable & Categories & Frequency & Percent & Antecedents of \\
\hline \multirow[t]{2}{*}{ Gender } & Male & 213 & 44.7 & buying \\
\hline & Female & 264 & 55.3 & \\
\hline \multirow{4}{*}{ Age } & Below 18 & 34 & 7.1 & behaviour \\
\hline & $18-22$ & 396 & 83.0 & \\
\hline & $23-25$ & 42 & 8.8 & \\
\hline & Above 25 & 5 & 1.0 & \\
\hline \multirow{4}{*}{ Class level } & 100 & 53 & 11.1 & \\
\hline & 200 & 177 & 37.1 & \\
\hline & 300 & 41 & 8.6 & \\
\hline & 400 & 206 & 43.2 & \\
\hline \multirow{6}{*}{ Area of major } & Not determined yet & 88 & 18.4 & \\
\hline & Accounting & 238 & 49.9 & \\
\hline & Finance & 65 & 13.6 & \\
\hline & Marketing & 7 & 1.5 & \\
\hline & Human resource & 55 & 11.5 & \\
\hline & Public administration & 24 & 5.0 & \\
\hline \multirow{2}{*}{ Nationality } & Ghanaian & 451 & 94.5 & \\
\hline & Non-ghanaian & 26 & 5.5 & \\
\hline \multirow[t]{3}{*}{ SES information } & Low class & 113 & 23.7 & Table 1. \\
\hline & Middle class & 159 & 33.3 & Descriptive Statistics \\
\hline & Upper class & 205 & 43.0 & on respondents \\
\hline
\end{tabular}

using the validated Time Affluence Scale developed by (Kasser and Sheldon, 2009). Indicators of Loan dependence and financial trouble were adapted from (Black, 2007). The specific indicators used to measure each of the constructs are shown in Table 2.

\section{Descriptive statistics of constructs}

Table 2 presents the mean scores and standard deviations of the respondents' compulsive buying tendencies and the others constructs. Compulsive buying behaviour recorded an overall mean of 3.24 an indication that the propensity of students buying compulsively exists though not too high. The indicators "At times, I feel guilty after buying something" and "There are times when I have a strong urge to buy clothing, tapes, jewellery, etc." had the highest scores (Mean $=4.12$ and 3.88 respectively; $\mathrm{SD}=2.199$ and 2.161 respectively). The indicator "Shopping is a way of relaxing and forgetting my problems" had the lowest average score $($ Mean $=2.44, \mathrm{SD}=1.924)$.

The overall mean score of the Material Value Scale was slightly above average $(M=3.86$, $\mathrm{SD}=2.049$ ), meaning that respondents endorse materialistic values to an extent. The indicator "My life would be better if I own certain things I do not have" had the highest score $(M=4.52, \mathrm{SD}=2.139)$ whilst "I like to own things that impress people" had the lowest score $(M=3.01, \mathrm{SD}=2.018)$.

The construct Financial Management had an overall mean score of 4.65, indicating that respondents exhibit a high level of personal management of finances. The indicator "I compare prices when I'm purchasing a product or service" had the highest mean score $(M=5.45, \mathrm{SD}=1.961)$ whilst "I keep a written or electronic record of my monthly expenses" had the lowest mean score $(M=3.72, \mathrm{SD}=2.025)$.

The construct loan dependence had an overall mean of 2.29. Given that the study adopted a seven-point Likert scale, this result suggests that dependence on loan is generally low among the sampled respondents. The indicator "I often buy products on credit" had the highest rating (Mean $=2.29, \mathrm{SD}=1.868$ ) whilst the indicator "I buy almost everything on credit" recorded the least average score (Mean $=2.24, \mathrm{SD}=1.91$ ). 
When I have money, I cannot help but spend part or all of it

IOften buy something I see in a store without planning, just because I've got to have it

Shopping is a way of relaxing and forgetting my problems

I Sometimes feel that something inside pushes me to go shoppin

There are times when I have a strong urge to buy clothing, tapes, jewellery, etc

At times, I feel guilty after buying something

I Often have a real desire to go shopping and buy something

I Have often bought things that I do not need even when I knew I had very little money

left

$3.17 \quad 2.181$

As soon as I enter a shopping centre, I want to go in a store and buy something

\section{Material values scale}

My life would be better if I own certain things I don't have

The things I own say a lot about how well I'm doing

I Like to own things that impress people

I Admire people who own expensive homes, cars, and clothes

I Like a lot of luxury in my life

I Would be happier if I could afford to buy more things

Some of the most important achievements in life include acquiring material

I Have all the things I really need to enjoy life

I Would not be any happier if I owned nicer things

The things I own are not all that important to me

I Put less emphasis on material things than most people I know

\section{Financial management}

I Compare prices when I'm purchasing a product or service

I Pay all my bills on time

I Keep a written or electronic record of my monthly expenses

I Stay within my budget or spending plan

\section{Loan dependence}

I Often buy products on credit

I Buy almost everything on credit

\section{Financial trouble}

I Had problems with monthly payments

Last year, I often had longer financial trouble

I Could not pay my loan instalment because of other expenditures

Time affluence

$2.76-1.971$

My life has been too rushed

I Have had plenty of spare time

I Have been racing from here to there

I Have had enough time to do what I need to do

I Have been able to take life at a leisurely pace

Table 2.

There have not been enough minutes in the day I have had enough time to do things 
With respect to the construct financial trouble, the overall mean was 2.83 which indicates that respondents experience trouble with finances at a lower level. The indicator "Last year, I often had longer financial trouble." had the highest score $(M=2.91, \mathrm{SD}=1.971)$ while the indicator "I could not pay my loan instalment because of other expenditures" had the lowest score $(M=2.76, \mathrm{SD}=1.065)$.

The construct time affluence had an overall mean score of 3.61 an indication that respondents generally have a balance in time. The indicator "I have felt like things have been really hectic". had the highest score $(M=4.23, \mathrm{SD}=1.938)$ while the indicator "My life has been too rushed" had the lowest score $(M=2.99, \mathrm{SD}=2.000)$.

\section{Data analysis technique}

Tests of the hypotheses of the study were done using the tested using the Partial Least Square (PLS) structural equation modelling (SEM) technique. SEM-based techniques are useful in testing and validating relationships and enable researchers to more effectively evaluate measurement models and structural paths involving latent constructs with multiitem indicator variables (Astrachan et al., 2014). All constructs were modelled using reflective indicators. First, an assessment of the measurement model aimed at achieving an adequate level of construct reliability and validity was done and results are as shown in Tables 3 and 4.

\section{Reliability and validity tests}

Reliability of each construct was measured using the composite reliability (CR) scores as recommended by Hair et al. (2012). All the constructs of the study proved to be adequately reliable as the scores for the composite reliability measure exceeded the recommended threshold of 0.70 (Fornell and Larcker, 1981; Nunnally and Bernstein, 1978).

\begin{tabular}{lcc}
\hline & CR & AVE \\
\hline CBB & 0.851 & 0.536 \\
FM & 0.748 & 0.608 \\
FT & 0.771 & 0.533 \\
LD & 0.905 & 0.827 \\
MVS & 0.835 & 0.599 \\
SES & 0.851 & 0.591 \\
TA & 0.778 & 0.637
\end{tabular}

Note(s): CR-Composite Reliability, AVE-Average Variance Extracted

$C B B$-Compulsive Buying Behaviour; FM-Financial Management; FT-Financial Trouble; LD-Loan Dependence; MVS-Materialistic Values; SES-Socioeconomic Status and TA-Time Affluence

Table 3. $\mathrm{CR}$ and AVE

\section{Antecedents of compulsive buying behaviour}

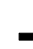

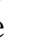

\begin{tabular}{|c|c|c|c|c|c|c|c|}
\hline Construct & $\mathrm{CBB}$ & FM & FT & LD & MVS & SES & TA \\
\hline $\mathrm{CBB}$ & 0.732 & & & & & & \\
\hline FM & -0.144 & 0.787 & & & & & \\
\hline FT & 0.030 & -0.121 & 0.820 & & & & \\
\hline LD & 0.247 & -0.234 & 0.155 & 0.909 & & & \\
\hline MVS & 0.313 & -0.002 & -0.012 & 0.072 & 0.748 & & \\
\hline SES & 0.072 & 0.007 & -0.018 & -0.081 & 0.011 & 0.769 & \\
\hline TA & 0.213 & -0.012 & -0.029 & 0.188 & 0.268 & 0.027 & 0.724 \\
\hline
\end{tabular}

Note(s): $C B B$-Compulsive Buying Behaviour; FM-Financial Management; $F T$-Financial Trouble; $L D$-Loan Dependence; $M V S$-Materialistic Values; SES-Socioeconomic Status and TA-Time Affluence 
To test for validity, convergent and discriminant validity of the instruments were checked. Convergent validity was assessed using the average variance extracted (AVE). The AVE scores of all the constructs met the recommended minimum threshold of 0.5 (Hair et al., 2013) as shown in Table 3. For discriminant validity to be assured, the square root of the AVE scores of the factors should be larger than the correlations between the constructs (Fornell and David, 1981). Again, the results of this test as presented in Table 4 demonstrate that discriminant validity is assured as the AVE scores for the factors were greater than the squared cross-correlations of the constructs.

Lastly, multicollinearity test was conducted to ensure that our results are not influenced negatively by collinearity problems. Test results as shown in Table 5 suggest the absence of multicollinearity problem as the Variance Inflation Factor (VIF) values for the constructs were far below the maximum threshold of 10 (O’Brien, 2007). Based on these satisfactory results the structural was assessed using the bootstrapping procedure. The final model showing the indicators included in the structural model analysis with their respective loadings is as shown in Figure 1.

\section{Discussion of results}

The bootstrapping results as shown in Table 5 suggest materialism has a positive and highly significant relationship $(\beta=0.279$, and $p$-value $=0.000)$ with CBB. This is an indication that

\begin{tabular}{llrcc}
\hline Hypothesis & Hypothesis & Coefficients & $p$ values & Remarks \\
\hline H1 & MVS $\rightarrow$ CBB & 0.291 & 0.000 & Accepted \\
H2 & SES $\rightarrow$ CBB & 0.013 & 0.187 & Rejected \\
H3 & FM $\rightarrow$ CBB & -0.128 & 0.005 & Accepted \\
H4 & TA $\rightarrow$ CBB & 0.216 & 0.000 & Accepted \\
H5 & CBB $\rightarrow$ LD & 0.211 & 0.000 & Accepted \\
H6 & LD $\rightarrow$ FT & 0.151 & 0.001 & Accepted \\
$R^{2}$ & CBB & 0.066 & & \\
& FT & 0.535 & & \\
$Q^{2}$ & LD & 0.019 & & \\
& CBB & 0.066 & & \\
& FT & 0.535 & & \\
& LD & 0.019 & &
\end{tabular}

Figure 1.

A structural model showing the antecedents and consequences of compulsive buying behaviour

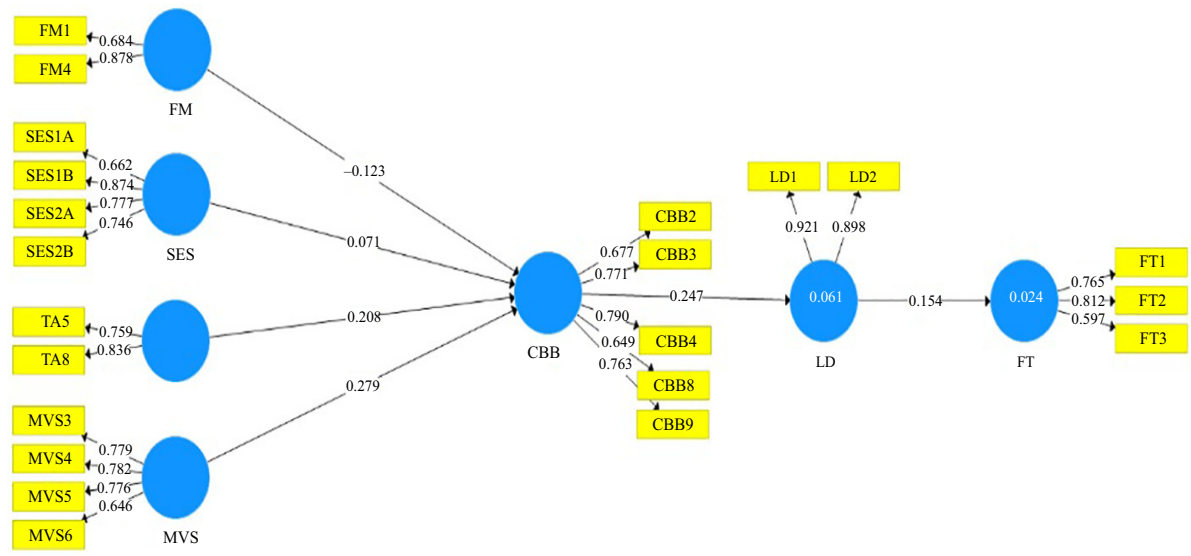


the tendency to buy compulsively is high when one an individual has a strong attachment to material possession. Materialistic individuals according to Donnelly et al. (2016) exhibit tendencies that suggest that happiness is tied up to material possessions and would therefore go lengths to acquire them. Indeed, materialistic individuals do not only acquire material possessions to obtain pleasure, arousal and gratification from them but also tend to buy compulsively to make up for their negative feelings. Several empirical studies (Dittmar et al., 2014; Donnelly et al., 2016; Johnson and Attmann, 2009; Unger and Raab, 2015) have reported results consistent with the fact that materialism has a positive effect on compulsive buying tendencies of individuals. This finding, therefore, supports the predicted hypothesis (H1).

Our results also suggest that socioeconomic status (SES) correlates positively with compulsive buying tendencies though the relationship is statistically insignificant. Notwithstanding this, the positive coefficient demonstrates that individuals who have higher levels of socio-economic status have greater motivation to buy compulsively compared with lower-level socioeconomic status people. Although individuals belonging to high social class are believed to be future oriented and rational in decision making and would usually save their incomes and delay gratification, it has been argued that individuals who perceive high social status as desirable are more prone to buy compulsively. Given that the frequency of buying status products or owning a number of possessions matters for an individual's status (Wang and Tsai, 2017), the quest for recognition of status may be associated with CBB. This result supports the findings of Michael (1998) and the argument of a shift in cultural identity and the unique characteristics of individuals with high socioeconomic status.

As expected, our results show a negative and highly significant relationship between financial management and $\mathrm{CBB}$. By implication, individuals with strong financial management background tend to have lower compulsive buying tendencies. The argument is that such individuals generally exert self-mastery over mundane finances and are able to take rational decisions on consumption. Regardless of their emotional feelings, such individuals are inherently driven to compare intended compulsive purchases with actual budgeted purchases which tends to limit them in terms of buying compulsively to alleviate negative feelings. Empirically, findings in most existing studies (Alemis and Yap, 2013; Bir, 2014; Taft et al., 2013) support the assertion that individuals with proper financial management practices are more likely to stick to their budgets even when plagued with negative emotions. This finding thus, confirms the stated hypothesis (H3) and the assertion that financial management is an important predictor of compulsive buying tendencies.

The result also shows a positive association between low time affluence and CBB. These findings indicate that $\mathrm{CBB}$ is high among individuals with heightened levels of busyness. It has been established that low time affluent individuals do not only experience negative emotional states like anxiety, insecurity, guilt etc. often but also cope poorly with stress (Giluk and Postlethwaite, 2015). Heightened levels of stress may induce compulsive buying in low time affluent individuals motivating them to continuously engage themselves with purchases and other inappropriate behaviour. As demonstrated by some studies, there is a strong positive connection between heightened levels of busyness and CBB (Manolis and Roberts, 2012; Lajeunesse and Rodríguez, 2012). The result supports the stated hypothesis (H4).

An important objective of this study was to ascertain whether $\mathrm{CBB}$ could be associated with Loan dependence of individuals. In line with the predicted hypothesis, we find CBB to be significant and positively associated with the tendency of an individual to depend on loans. This is an indication that the tendency to borrow or resort to other forms of credit is high with individuals who buy compulsively. This result in effect supports the argument of existing empirical studies (Aw et al., 2018; Brougham et al., 2011; Prawitz et al., 2006). As pointed out by Aw et al. (2018), the persistent purchase of material goods as a result of negative feelings
Antecedents of compulsive buying behaviour

$+$


leads to dependence on credit as incomes of compulsive buyers at a point may not be enough to support such lifestyle.

Lastly, we find a positive and significant relationship between Loan dependence and Financial trouble which suggests that the likelihood of getting into financial trouble is high among individuals who depend on loans as a result of their compulsive buying tendencies. This finding is supported by a number of existing studies (Aw et al., 2018; Mccarthy, 2011).

\section{Moderation analysis}

To ascertain whether in the presence of strong financial management background the relationship between the identified predictors and $\mathrm{CBB}$ as well as the effect of $\mathrm{CBB}$ on loan dependence could change in any way, we performed a moderation analysis with financial management as the moderator.

\section{Discussion of moderation results}

As shown in Table 6, the interaction between financial management and materialism resulted in a negative and highly significant relationship with CBB. This is a demonstration that good financial management background moderates the relationship between materialism and CBB. By implication, regardless of one's endorsement and indulgence in materialistic values, there would be minimal motivation to engage in CBB if individuals have developed their financial management skills to the extent that it is ingrained in them. As Asad Shahjehan (2012b) surmise when materialistic individuals have a strong mastery over the use of their finances, the likelihood engaging in $\mathrm{CBB}$ as a means of combating negative emotions would be low. Financial management skills are therefore relevant in minimizing the tendency to buy compulsively by materialistic individuals.

The interaction of financial management with time affluence also yielded a negative path coefficient in line with our expectation but statistically insignificant relationship. Similarly, the interactive effect of financial management on loan dependence was negative an indication that the tendency to resort to loans will be low for a compulsive buyer with strong financial management background. The interaction of financial management and socioeconomic status however, yielded a positive relationship with $\mathrm{CBB}$ an indication financial management failed to moderate the predicted relationship.

\section{Conclusion}

Research into why some individuals consistently spend beyond their needs and the inability to resist the inner urge to make repeated purchases has been on ascendency in recent times. While literature on this subject matter is rich, extant studies have focused predominantly on the antecedents and consequences of compulsive buying behaviour (CBB). In particular, the

Table 6.

Moderation results

\begin{tabular}{lccc}
\hline Hypothesis path & Coefficients & $p$ values & Remarks \\
\hline $\mathrm{FM}^{*} \mathrm{MVS} \rightarrow \mathrm{CBB}$ & -0.084 & 0.056 & Accepted \\
$\mathrm{FM} * \mathrm{SES} \rightarrow \mathrm{CBB}$ & 0.013 & 0.799 & Rejected \\
$\mathrm{FM} * \mathrm{TA} \rightarrow \mathrm{CBB}$ & -0.030 & 0.291 & Rejected \\
$\mathrm{FM}^{*} \mathrm{CBB} \rightarrow \mathrm{LD}$ & -0.054 & 0.561 & Rejected
\end{tabular}

Note(s): $F M^{*} M V S$-Financial Management interacting with Materialism, $F M * T A$-Financial Management interacting with Time Affluence, $F M * S E S$-Financial Management interacting with Socioeconomic Status: $F M^{*} C B B-F i n a n c i a l$ Management interacting with Compulsive buying 
role of materialistic values and its relationship with $\mathrm{CBB}$ has received significant research attention with most studies concluding that materialism correlates positively with $\mathrm{CBB}$ (Islam et al., 2018). The current study examines the materialistic values and CBB-nexus from a developing country setting while highlighting the role of time affluence and socio-economic status of an individual on the tendency to buy compulsively. Additionally, the study investigates the effect of $\mathrm{CBB}$ on the tendency of an individual to depend on loans and the risks of falling into financial trouble. Unlike most existing studies however, this study ascertains moderating role of financial management in these relationships.

In line with our expectation and consistent with existing studies, we find materialism, socioeconomic status, time affluence and financial management to be important predictors of CBB. CBB was found to be positively associated with loan dependence while the risk of falling into financial trouble was found to be high among individuals who depend on loans to buy compulsively. Our results suggest financial management skills moderate favourably the effect of these relationships. While the findings of this study emphasize the role of financial management in dealing with addictive behaviours such as the tendency to buy compulsively, the results also indicate that CBB may not only lead to short-term problems in life (e.g. increased stress, low grades, problems with family and friends) as documented in empirical studies but may also have long term consequences such as debt burdens and getting an individual into financial trouble.

Taken together, our findings suggest equipping young people with financial management skills is key in minimizing their compulsive buying tendencies and the consequences thereof. Given that the tendency to buy compulsively is suppressed even among high materialistic individuals when financial management skills is strong, an important way of changing the attitude of individuals caught in this addictive behaviour is to improve their financial management skills. On the basis of this we recommend that any intervention meant to address the compulsive buying tendency of individuals especially the youth should among other things focus on financial education and counselling directed at improving financial management skills. Specifically, the teaching of basic personal financial management skills such as cash and credit management, budgeting, and savings at school should form an important component of the training of young people at the foundation stage of their schooling life.

Also, as financial management skills are not only obtained through the formal education system, parents, who play an active role in the informal socialization development of their wards should nurture the financial knowledge and skills of their children. This would go a long way to expose the young people to financial concepts, planning of finances and improvement in their capacity to understand and handle their finances.

Like all research, this study suffers from potential limitations including the fact the sample is primarily made up of university students thereby not representing a greater spectrum of consumers. Using a more diverse sample could help improve the generalization of the findings. Also, the study only examined students who are likely to have compulsive buying tendencies rather than identified chronic compulsive buyers alongside its connectivity with an array of other disorders. The results should, therefore, be interpreted with care as tendencies most certainly change overtime. These limitations, however, provide important avenues for future research.

\section{References}

Abraham, E.M. (2016), "Determinants of Household Socio-economic Status in an Urban Setting in Ghana”, Ghana Journal of Development Studies, Vol. 13 No. 1, pp. 97-114.

Achtziger, A., Hubert, M., Kenning, P., Raab, G. and Reisch, L. (2015), "Debt out of control: the links between self-control, compulsive buying, and real debts", Journal of Economic Psychology, Vol. 49, pp. 141-149. 
Adler, N.E. and Ostrove, J.M. (1999), "Socioeconomic status and health: what we know and what we don't”, Annals of the New York Academy of Sciences, Vol. 896 June, pp. 3-15.

Ahmed, M. (2018), "Compulsive buying behavior: antecedents, consequences and prevalence in shopping mall consumers of an emerging economy", Pakistan Journal of Commerce and Social Sciences, Vol. 12 No. 2, pp. 548-570.

Alemis, M.C. and Yap, K. (2013), "The role of negative urgency impulsivity and financial management practices in compulsive buying", Australian Journal of Psychology, Vol. 65 No. 4, pp. 224-231.

Asad, S. (2012), "The effect of personality on impulsive and compulsive buying behaviors", African Journal of Business Management, Vol. 6 No. 6, pp. 2187-2194.

Astrachan, C.B., Patel, V.K. and Wanzenried, G. (2014), "A comparative study of CB-SEM and PLSSEM for theory development in family firm research", Journal of Family Business Strategy, Vol. 5 No. 1, pp. 116-128.

Aw, E.C.X., Cheah, J.H., Ng, S.I. and Sambasivan, M. (2018), "Breaking compulsive buying-financial trouble chain of young Malaysian consumers", Young Consumers, Vol. 19 No. 3, pp. 328-344.

Bir, J.S. (2014), "Knowledge, attitude and their effect on the recently graduated employees' financial management practices and satisfaction", Economic Literature, Vol. 12, pp. 69-81.

Black, D.W. (2007), “A review of compulsive buying disorder”, World Psychiatry, Vol. 6 No. 1, p. 14.

Brougham, R.R., Jacobs-Lawson, J.M., Hershey, D.A. and Trujillo, K.M. (2011), "Who pays your debt? An important question for understanding compulsive buying among American college students", International Journal of Consumer Studies, Vol. 35 No. 1, pp. 79-85.

Chaplin, L.N. and John, D.R. (2007), "Growing up in a material world: age differences in materialism in children and adolescents", Journal of Consumer Research, Vol. 34 No. 4, pp. 480-493.

Ching, B.H.H. and Wu, X. (2018), "Parental conflicts and materialism in adolescents: emotional insecurity as a mediator", Journal of Adolescence, Vol. 69 July, pp. 189-202.

Cirino, P.T., Chin, C.E., Sevcik, R.A., Wolf, M., Lovett, M. and Morris, R.D. (2002), "Measuring socioeconomic status: reliability and preliminary validity for different approaches", Assessment, Vol. 9 No. 2, pp. 145-155.

Dittmar, H. (2005), "Compulsive buying - a growing concern? An examination of gender, age, and endorsement of materialistic values as predictors", British Journal of Psychology, Vol. 96 No. 4, pp. 467-491.

Dittmar, H., Bond, R., Hurst, M. and Kasser, T. (2014), "The relationship between materialism and personal well-being: a meta-analysis", Journal of Personality and Social Psychology, Vol. 107 No. 5, pp. 879-924.

Donnelly, G.E., Ksendzova, M., Howell, R.T., Vohs, K.D. and Baumeister, R.F. (2016), "Buying to blunt negative feelings: materialistic escape from the self", Review of General Psychology, Vol. 20 No. 3, pp. 272-316.

Duh, H. and Thorsten, T. (2019), "Preventing compulsive shopping among young South-Africans and Germans", Young Consumers, Vol. 20 No. 1, pp. 29-43.

Faber, R.J. and Christenson, G.A. (1996), "In the mood to buy: differences in the mood states experienced by compulsive buyers and other consumers", Psychology and Marketing, Vol. 13 No. 8, pp. 803-819.

Flight, R.L., Rountree, M.M. and Beatty, S.E. (2012), "Feeling the urge: affect in impulsive and compulsive buying", Journal of Marketing Theory and Practice, Vol. 20 No. 4, pp. 453-466.

Fornell, C. and David, L.F. (1981), Structural Equation Models With Unobservable Variables and Measurement Error: Algebra and Statistics., Vol. 18 No. 3, pp. 382-388.

Gärling, T., Krause, K., Gamble, A. and Hartig, T. (2014), "Emotional well-being and time pressure", PsyCh Journal, Vol. 3 No. 2, pp. 132-143. 
Gaur, K.L. (2013), "Socio-economic status measurement scale: thirst area with changing concept for socio-economic status", International Journal of Innovative Research and ..., Vol. 2 No. 9, pp. 139-145.

Giluk, T.L. and Postlethwaite, B.E. (2015), "Big Five personality and academic dishonesty: a metaanalytic review", Personality and Individual Differences, Vol. 72, pp. 59-67.

Antecedents of compulsive buying behaviour

Hair, J.F., Sarstedt, M., Ringle, C.M. and Mena, J.A. (2012), "An assessment of the use of partial least squares structural equation modeling in marketing research", Journal of the Academy of Marketing Science, Vol. 40 No. 3, pp. 414-433.

Hair, J.F., Ringle, C.M. and Sarstedt, M. (2013), "Partial least squares structural equation modeling: rigorous applications, better results and higher acceptance", Long Range Planning, Vol. 46 Nos 1-2, pp. 1-12.

Hollander, E. and Rosen, J. (1998), "Impulsivity impulse-control disorders", Journal of Psychopharmacology, Vol. 14 No. 2, pp. 39-44.

Huang, J.T. and Hsieh, H.H. (2011), "Linking socioeconomic status to social cognitive career theory factors: a partial least squares path modeling analysis", Journal of Career Assessment, Vol. 19 No. 4, pp. 452-461.

Hudson, C., Young, J., Anong, S., Hudson, E. and Davis, E. (2017), “African American financial socialization", Review of Black Political Economy, Vol. 44 Nos 3-4, pp. 285-302.

Iqbal, N. and Aslam, N. (2016), "Materialism, depression, and compulsive buying among university students", The International Journal of Indian Psychology, Vol. 3 No. 2, pp. 92-102.

Islam, T., Sheikh, Z., Hameed, Z., Khan, I.U. and Azam, R.I. (2018), "Social comparison, materialism, and compulsive buying based on stimulus-response-model: a comparative study among adolescents and young adults", Young Consumers, Vol. 19 No. 1, pp. 19-37.

Johnson, T. and Attmann, J. (2009), "Compulsive buying in a product specific context: clothing", Journal of Fashion Marketing and Management, Vol. 13 No. 3, pp. 394-405.

Kasser, T. and Sheldon, K.M. (2009), "Time affluence as a path toward personal happiness and ethical business practice: empirical evidence from four studies", Journal of Business Ethics, Vol. 84 No. 2, pp. 243-255.

Kellett, S. and Bolton, J.V. (2009), "Compulsive buying : a cognitive - behavioural model”, Clinical Psychology and Psychotherapy, Vol. 99 February, pp. 83-99.

Khandelwal, R., Kolte, A., Veer, N. and Sharma, P. (2021), "Compulsive buying behaviour of credit card users and affecting factors such as financial knowledge, prestige and retention time: a crosssectional research", Vision, pp. 1-9.

Lajeunesse, S. and Rodríguez, D.A. (2012), "Mindfulness, time affluence, and journey-based affect: exploring relationships", Transportation Research Part F: Traffic Psychology and Behaviour, Vol. 15 No. 2, pp. 196-205.

Lim, S.H., Lee, S. and Kim, D.J. (2017), "Is online consumers' impulsive buying beneficial for e-commerce companies? An empirical investigation of online consumers' past impulsive buying behaviors", Information Systems Management, Vol. 34 No. 1, pp. 85-100.

Manolis, C. and Roberts, J.A. (2012), "Subjective well-being among adolescent consumers: the effects of materialism, compulsive buying, and time affluence", Applied Research in Quality of Life, Vol. 7 No. 2, pp. 117-135.

Maraz, A., Eisinger, A., Hende, B., Urbán, R., Paksi, B., Kun, B., Kökönyei, G., Griffiths, M.D. and Demetrovics, Z. (2015), "Measuring compulsive buying behaviour: psychometric validity of three different scales and prevalence in the general population and in shopping centres", Psychiatry Research, Vol. 225 No. 3, pp. 326-334.

Martinez-Novoa, L.M. and Hodges, N. (2016a), "Identifying compulsive buyers: an examination of existing scales from the perspective of medical practitioners", in Let's Get Engaged! Crossing the Threshold of Marketing's Engagement Era, Springer, Cham, pp. 379-384. 
Martinez-Novoa, L.M. and Hodges, N.N. (2016b), "Beyond shopaholism: a socio-cultural examination of compulsive clothing buying behavior", International Textile and Apparel Association Annual Conference Proceedings, Vol. 73 No. 1, Iowa State University Digital Press.

Mccarthy, Y. (2011), "Behavioural characteristics and financial distress", Conference on Household Finance and Consumption.

Mestre-Bach, G., Steward, T., Jiménez-Murcia, S. and Fernández-Aranda, F. (2017), "Differences and similarities between compulsive buying and other addictive behaviors", Current Addiction Reports, Vol. 4 No. 3, pp. 228-236.

Michael, W. (1998), "Socio-economic status, delay of gratification, and impulse buying", Journal of Economic Psychology, Vol. 19 No. 3, pp. 295-320.

Mittal, V., Huppertz, J.W. and Khare, A. (2008), "Customer complaining: the role of tie strength and information control", Journal of Retailing, Vol. 84 No. 2, pp. 195-204.

Moon, M.A., Szabist, S., Pakistan, I., Rasool, H., Rawalpindi, B., Pakistan, P. and Attiq, S. (2015), "Personality and irregular buying behavior: adaptation and validation of core self evaluation personality trait model in consumer impulsive and compulsive buying behavior", Journal of Marketing and Consumer Research Journal, Vol. 15, pp. 121-132.

Nilsson, E., Gärling, T. and Marell, A. (2017), "Effects of time pressure, type of shopping, and store attributes on consumers' satisfaction with grocery shopping", International Review of Retail, Distribution and Consumer Research, Vol. 27 No. 4, pp. 334-351.

Nunnally, J.C. and Bernstein, I.H. (1978), Psychometric Theory, McGraw-Hill.

Oakes, M. (2012), "Measuring socioeconomic status”, Behavioral Social Sciences Research.

O'Brien, R.M. (2007), "A caution regarding rules of thumb for variance inflation factors", Quality and Quantity, Vol. 41 No. 5, pp. 673-690.

Palan, K.M., Morrow, P.C., Trapp, A. and Blackburn, V. (2011), "Compulsive buying behavior in college students: the mediating role of credit card misuse", Journal of Marketing Theory and Practice, Vol. 19 No. 1, pp. 81-96.

Parrotta, J.L. and Johnson, P.J. (1998), "The impact of financial attitudes and knowledge on financial management and satisfaction of recently married individuals", Journal of Financial Counseling and Planning, Vol. 9 No. 2, pp. 59-75.

Pham, T.H., Yap, K. and Dowling, N.A. (2012), "The impact of financial management practices and financial attitudes on the relationship between materialism and compulsive buying", Journal of Economic Psychology, Vol. 33 No. 3, pp. 461-470.

Prawitz, A., Garman, E.T., Sorhaindo, B., O’Neill, B., Kim, J. and Drentea, P. (2006), "InCharge financial distress/financial well-being scale: development, administration, and score interpretation", Journal of Financial Counseling and Planning, Vol. 17 No. 1.

Ramalho, T.B. and Forte, D. (2019), "Financial literacy in Brazil-do knowledge and self-confidence relate with behavior?", RAUSP Management Journal, Vol. 54, pp. 77-95.

Richins, M.L. (2004), "The material values scale: measurement properties and development of a short form”, Journal of Consumer Research, Vol. 31 No. 1, pp. 209-219.

Richins, M.L. and Dawson, S. (1992), "A consumer values orientation for materialism and its measurement: scale development and validation”, Journal of Consumer Research, Vol. 19 No. 3, pp. 303-316.

Rindfleisch, A., Burroughs, J.E. and Denton, F. (1997), "Family structure, materialism, and compulsive consumption", Journal of Consumer Research, Vol. 23 No. 4, p. 312.

Roberts, J.A. and Jones, E. (2001), "Money attitudes, credit card use, and compulsive buying among American college students", Journal of Consumer Affairs, Vol. 35 No. 2, pp. 213-240.

Silvera, D.H., Lavack, A.M. and Kropp, F. (2008), "Impulse buying: the role of affect, social influence, and subjective wellbeing”, Journal of Consumer Marketing, Vol. 25 No. 1, pp. 23-33. 
Sulehri, N.A. and Ahmed, M. (2017), "Theory of reasoned action and retail agglomerations buying behavior for urban consumers", The Business and Management Review, Vol. 9 No. 2, pp. 263-266.

Taft, M.K., Hosein, Z.Z. and Mehrizi, S.M.T. (2013), "The relation between financial literacy, financial wellbeing and financial concerns", International Journal of Business and Management, Vol. 8 No. 11, pp. 63-73.

Unger, A. and Raab, G. (2015), "The dark side of globalization and consumption: how similar are Chinese and German consumers toward their proneness to compulsive buying?", Journal of Asia-Pacific Business, Vol. 16 No. 1, pp. 4-20.

Wang, Y.C. and Tsai, C.T.S. (2017), "Feeling better when buying more? Harmonious passion and obsessive passion in online food group buying", British Food Journal, Vol. 119 No. 6, pp. $1263-1275$.

Yingjiao, Y. (2008), “The influence of public self-consciousness and materialism on young consumers' compulsive buying", Young Consumers, Vol. 9 No. 1, pp. 37-48.

\section{Corresponding author}

Godfred Matthew Yaw Owusu can be contacted at: gmowusu@gmail.com

For instructions on how to order reprints of this article, please visit our website: 